\title{
Boron-doped diamond modified with gold nanoparticles for the characterization of bovine serum albumin protein
}

\author{
Ángela I. López-Lorente*, Javier Izquierdo, Christine Kranz, Boris Mizaikoff \\ Institute of Analytical and Bioanalytical Chemistry, Ulm University, Ulm, Germany
}

\section{A R T I C L E I N F O}

\section{Article history:}

Received 1 June 2016

Received in revised form 22 October 2016

Accepted 24 October 2016

Available online xxx

\section{Keywords:}

Mid-infrared spectroscopy

IR-ATR

Electrochemistry

Atomic force microscopy

Gold nanoparticles

Bovine serum albumin

\begin{abstract}
A B S T R A C T
Boron-doped diamond (BDD) has been modified with bare gold nanoparticles (AuNPs) for the investigation of bovine serum albumin (BSA) protein films. First, the BDD electrode was aminoterminated via silanization with (3-aminopropyl)triethoxysilane (APTES). Then, the AuNPs were synthesized using a stainless steel-assisted method, and immobilized at the APTES-modified BDD surface (BDD/APTES/AuNPs). The resulting morphology of both modification steps was characterized using atomic force microscopy (AFM). Besides, the synthesis of AuNPs was in-situ monitored via infrared attenuated total reflection (IR-ATR) spectroscopy using a combined IR-ATR-EC-AFM system taking advantage of surface enhanced IR absorption (SEIRA) effects induced by the AuNPs. The modified conductive IR-ATR BDD waveguide was employed to investigate spectroelectrochemically films of globular and fibrilized BSA, which were deposited onto the AuNPs-modified surface. SEIRA spectroscopy enabled the discrimination between globular and fibril aggregates of BSA via curve fitting of amide I band revealing a major contributions of crossed $\beta$-sheet structures within the fibril aggregates. Finally, preliminary square-wave voltammetry experiments showed that the spectroelectrochemical setup has potential for in-situ electrochemical characterization of such protein films.
\end{abstract}

(c) 2016 Elsevier B.V. All rights reserved.

\section{Introduction}

Mid-infrared (MIR) spectroscopy is a useful technique for protein analysis [1] owing to the vibrational resonances arising from the polypeptide backbone and/or side chains of the proteins, providing information on their secondary structure in a label-free fashion. The amide I band of the MIR spectra of proteins is mainly associated with the $\mathrm{C}=\mathrm{O}$ stretching vibration, while the amide II band arises mainly from $\mathrm{N}-\mathrm{H}$ bending and $\mathrm{C}-\mathrm{N}$ stretching vibrations of the peptide backbone [2]. Due to the different hydrogen-bonding environments within the different secondary structures of proteins, namely $\alpha$-helix, $\beta$-sheet, etc., the amide I band can provide information about the protein structure [3]. Among the various IR techniques used for protein analysis, such as infrared reflection absorption spectroscopy (IRRAS) [4,5], twodimensional IR [6,7], infrared difference spectroscopy [8], etc., infrared attenuated total reflection (IR-ATR) spectroscopy has been widely employed for investigating proteins solutions [3,9-11] as well as e.g. to evaluate the formation of amyloid fibrils of proteins [12-16].

\footnotetext{
* Corresponding author.

E-mail address: angela.lopez@uni-ulm.de (Á.I. López-Lorente).
}

In addition, surface-enhanced infrared absorption spectroscopy (SEIRAS) is attracting great attention also for protein analysis [17] due to the higher sensitivity provided by the SEIRA substrate usually a rough noble metal (nanostructured) film - deposited on top of an ATR waveguide. SEIRAS measurements are usually performed at individual metal islands of nanoparticles as well as e.g. periodic particle-array films [18]. Recently, our research team has reported on the SEIRA effect at gold nanoparticles (AuNPs) observing the enhancement of water absorption bands [19]. The AuNPs were synthesized mediated by stainless steel as solid reducing agent [19-21].

Diamond has excellent optical properties in the MIR spectral regime such as low self-absorption and scattering, high refractive index and transparency over a wide spectral range [22,23]. Borondoped diamond is attracting significant attention as transparent electrode material due to its broad spectroscopic window together with its electrochemical properties such as low background current and wide working potential window [24,25]. The diamond ATR crystal with a BDD layer on top results in an IR transparent electrode (ITE) enabling spectroelectrochemical measurements in the MIR region. In contrast, most other IR transparent materials (e.g. silicon, silver halides, ZnSe, etc.) are insulators. Besides, the high resistance towards (bio)fouling makes BDD electrodes 
particularly advantageous for the electrochemical investigation of biomolecules [26,27]. The electrochemical properties of BDD electrodes can be further improved via its decoration with AuNPs $[28,29]$, while the same strategy additionally promotes SEIRA effect on BDD-ITEs [30,31]. In addition, complementarily atomic force microscopy (AFM) measurements for the characterization of the morphology of the modified surface and proteins can be easily performed at the flat homoepitactically BDD surfaces.

The properties mentioned above render AuNPs-modified BDD surfaces of particular interest for multi-functional analytical platforms suitable for studying proteins using IR-spectroscopy, electrochemistry and AFM. IR-ATR in combination with spectroelectrochemistry and AFM has first been demonstrated by Neubauer et al. providing simultaneous IR and topographical information during the electro-polymerization of 3,4-ethylenedioxothiophene (EDOT) [25].

Bovine serum albumin (BSA) is a globular protein composed of 583 amino acids with a molecular weight of approximately $66.5 \mathrm{KDa}$. The secondary structure of BSA is dominated by $\alpha$-helices (around 67\%) [32]. BSA protein can be adsorbed onto AuNPs owing to its external thiol group [33], and its interaction with hydrogen-terminated BDD electrodes is reported to enable its direct oxidation [26]. In addition, protein aggregation leading to the formation of fibrils has been related to some neurodegenerative diseases [34]. It has been reported that BSA protein can form amyloid-like fibrils rich in $\beta$-sheet structures [35,36]. MIR spectroscopy is able to determine the conformation of proteins amyloid fibrils aggregates [12-16], since they are characterized by crossed $\beta$-sheet structures $\left(\sim 1620 \mathrm{~cm}^{-1}\right)$, whereas the native $\beta$-sheet structures appears at around $1630 \mathrm{~cm}^{-1}$ [37].

Herein, we report the combination of SEIRA, using AuNPs produced by stainless steel O-ring assisted method, in ATR mode in combination with electrochemical and scanning probe microscopic (i.e. AFM) techniques for the characterization of BSA protein in aqueous samples. This complementary approach combines the chemical information provided by MIR spectroscopy with the signal enhancement due to the presence of the AuNPs, electrochemical information and the high spatial resolution provided by AFM, thus providing the opportunity of performing chemical and structural analysis of the protein sample. The topological changes associated with each modification step of the surface of the ATR crystal were followed by AFM. IR spectroscopy enabled the monitoring of the synthesis of the AuNPs as well as the subsequent IR-enhanced determination of BSA protein. BSA protein films were also indirectly characterized via square wave voltammetry by the oxidation of the AuNPs in phosphate buffer solution, showing the potential of the modified BDD surface for complementary electrochemical measurements. Finally, the formation of fibril aggregates of BSA protein was evaluated by AFM and IR, resulting in an increase of the presence of $\beta$-sheet structures as reflected in the amide I band.

\section{Materials and methods}

\subsection{Reagents}

(3-aminopropyl)triethoxysilane (APTES) 98\% for surface modification and hydrogen tetrachloroaurate (III) trihydrate ACS 99.99\% used for synthesizing the gold nanoparticles were purchased from Alfa Aesar (Karlsruhe, Germany). Potassium hydroxide (analytical grade) and sulfuric acid were obtained from Merck (Darmstadt, Germany) and VWR Chemicals BDH Prolabo, respectively. Phosphate buffer solution of $\mathrm{pH} 5.65$ was prepared using $\mathrm{NaH}_{2} \mathrm{PO}_{4}$ and $\mathrm{Na}_{2} \mathrm{HPO}_{4}$ from Merck. Albumin from bovine serum (BSA) (Sigma A9418) and dimethyl sulfoxide (DMSO) were provided by Sigma-
Aldrich Co. (St. Louis, MO). $10 \mathrm{mg} \mathrm{mL}^{-1}$ stock solution of the protein was prepared. All solutions were prepared using ultrapure water (Elga water system, conductivity $18.0 \mathrm{M} \Omega \mathrm{cm}$; Elga Labwater, VWS Deutschland GmbH, Celle, Germany).

\subsection{Combined SEIRA-ATR-EC-AFM setup}

A hemispherical diamond crystal (diameter: $2 \mathrm{~mm}$ ) was acquired from Harrick Scientific (Pleasantville, NY, USA), and modified with oxygen-terminated BDD as described in detail elsewhere [25]. Briefly, BDD deposition was carried out via microwave plasma chemical vapor deposition (MWP-CVD). A resulting 100-nm thick layer of BDD (boron content of approx. $5 \cdot 10^{20} \mathrm{~cm}^{-3}$ ) covered the crystal, whose sides were subsequently etched with $\mathrm{Ar} / \mathrm{O}_{2}{ }^{-}$plasma in order to remove the BDD layer from the sides of the ATR crystal, thereby leaving only a small section protected from this etching, which can then be used for electrical contacting the BDD electrode. The BDD-modified diamond ATR crystal was placed in a custom-made polyether ether ketone (PEEK) platform, integrated in an adapted AFM sampling assembly with the planar conductive surface facing up, also equipped with an electrochemical liquid cell. Scheme 1 shows the experimental setup for the combined measurements.

IR-ATR measurements were performed using a home-made combined setup previously described [25]. As IR source, a FTIRspectrometer (Matrix-M IRcube, Bruker Optik GmbH, Ettlingen Germany) was used. This spectrometer was the only instrumental device located outside the custom-built glove box, used to avoid fluctuations of water vapor and $\mathrm{CO}_{2}$ during the IR experiments constantly purged with dry air. An open window was produced at the location where the IR-light was emitted from the FTIRspectrometer, and a series of off-axis parabolic gold mirrors were used to collimate and focus the IR radiation to one side of the hemispherical surface of the crystal (as mounted in the AFM sample holder) as well as to focus the attenuated radiation onto the detector. The latter consisted of an external liquid nitrogen cooled D316/6 MCT-detector (Infrared Associates Stuart, FL, USA), also placed inside the glove-box. A top-down AFM scanner could be placed on top of the sample holder also inside the glove box. All the necessary electric connections with controllers and computers were performed with appropriate windows in the glove-box for the cables. All IR spectra reported here were acquired at a spectral resolution of $2 \mathrm{~cm}^{-1}$ and $40 \mathrm{kHz}$ frequency averaging 400 spectra (200 in the case of monitoring the synthesis of the AuNPs). Prior to analyzing the enhancement observed on the water absorption features during in-situ synthesis of AuNPs, a background spectrum of the tetrachloroauric acid solution was collected. Measurements were collected at room temperature (approx. $20^{\circ} \mathrm{C}$ ).

For AFM measurements, a 5500 scanning probe microscope by Keysight Technologies (Santa Rosa, CA, USA) equipped with a $90 \times 90 \mu \mathrm{m}$ scanner was used, which is integrated into the combined setup as previously shown $[25,38]$ and discussed above. AFM dynamic mode measurements were performed using silicon cantilevers (NCL-W) from Nanoworld (Neuchâtel, Switzerland) with a resonant frequency of $190 \mathrm{kHz}$ and a nominal force constant $48 \mathrm{~N} \mathrm{~m}^{-1}$. AFM measurements were performed maintaining a constant amplitude vibration of $85 \%$ with respect to the amplitude of the oscillation before approaching to the surface. Roughness parameters of the non-modified and APTES-modified BDD surfaces were calculated from AFM measurements recorded at 5 different spots at the sample surface following ISO 25178 standard, and were reported as root mean square height values $\left(R_{\text {rms }}\right)$.

Finally, electrochemical experiments were performed with an 842B potentiostat from CH Instruments (Austin, TX, USA) in 3electrode configuration, with the modified BDD crystal as the working electrode, an $\mathrm{Ag} / \mathrm{AgCl}$ (sat.) reference electrode, and a 


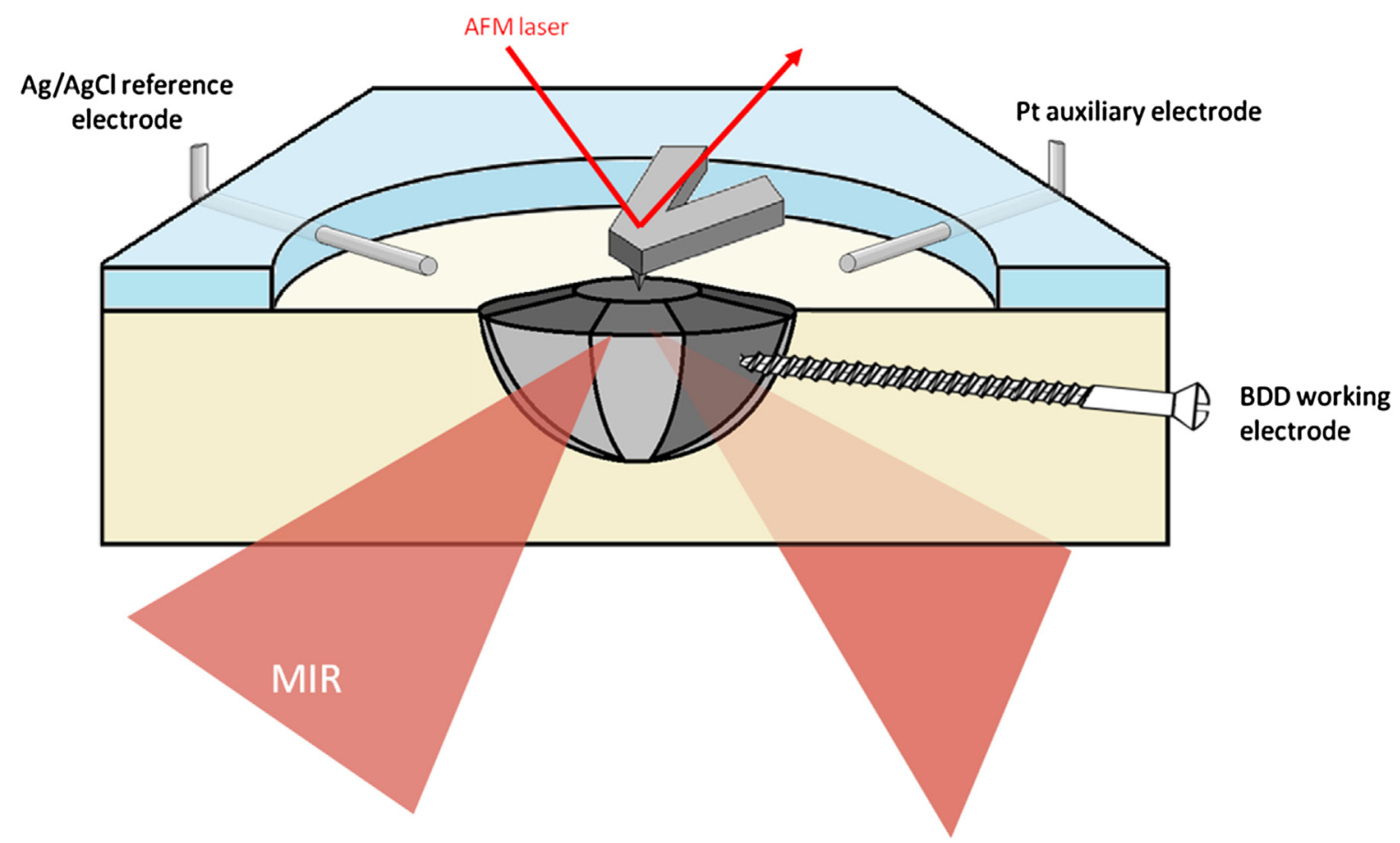

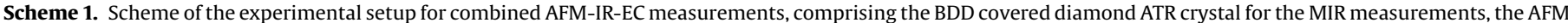

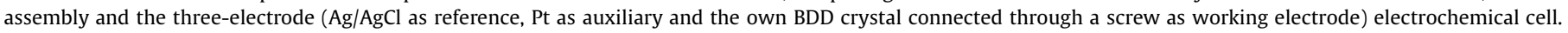

platinum wire as counter-electrode. All reported potentials are referred to the $\mathrm{Ag} / \mathrm{AgCl}$ (sat.) reference electrode.

\subsection{Amino termination of BDD-modified diamond ATR crystals}

The BDD layer on the top of the diamond ATR crystal was amino-terminated via silanization with (3-aminopropyl)triethoxysilane (APTES) in order to improve the immobilization of gold nanoparticles during the in-situ synthesis at the ATR crystal surface. For this purpose, cyclic voltammograms (CVs) were performed at the BDD-modified crystal in $0.1 \mathrm{M} \mathrm{H}_{2} \mathrm{SO}_{4}$ solution ( 20 cycles between 0 and $2.5 \mathrm{~V}$ at $0.1 \mathrm{~V} \mathrm{~s}^{-1}$ ). Then, after rinsing the crystal with Millipore water, it was treated with a $1 \%$ wt. $\mathrm{KOH}$ solution for $5 \mathrm{~min}$ in order to activate the $\mathrm{OH}^{-}$groups at the surface [39]. Subsequently, the crystal was immersed in a $2 \%(v / v)$ APTES solution in ethanol for 5 min to achieve an amino-terminated BDD surface $[40,41]$. After that, the crystal was rinsed with ethanol and Milli-Q water and dried under Argon flow.

\subsection{Preparation and characterization of the SEIRA substrate}

Gold nanoparticles forming the SEIRA substrate were directly synthesized at the BDD-modified diamond ATR crystal. AuNPs were formed mediated by stainless steel as solid reducing agent, as previously reported [20]. A stainless steel O-ring with an inner and outer diameter of 6.85 and $12.7 \mathrm{~mm}$, respectively, and a thickness of $1.4 \mathrm{~mm}$ was placed at the BDD surface (approx. $150 \mathrm{~mm}^{2}$ of the stainless steel O-ring surface was in contact with the $0.1 \%$ (wt.) Au solution). As the stainless steel reacts with the $\mathrm{HAuCl}_{4}$, AuNPs are formed in-situ and subsequently attach to the ATR surface via interaction with APTES. The stainless steel O-ring was in contact with the $\mathrm{HAuCl}_{4}$ solution for approx. $15 \mathrm{~min}$. In order to characterize the formation of the AuNPs, additional experiments monitoring the process at longer exposure times were performed. Afterwards, the stainless steel ring and the remaining $\mathrm{HAuCl}_{4}$ solution were removed. The surface was finally rinsed with Milli-Q water and dried under Argon flow. AuNPs with a size distribution of $23 \pm 10 \mathrm{~nm}$ are obtained via this synthesis route.

Linear sweep voltammetry (LSV) experiments were performed in $0.1 \mathrm{M}$ phosphate buffer solution ( $\mathrm{pH} 5.65$ ) at $0.1 \mathrm{~V} \mathrm{~s}^{-1}$ from 0 to $-0.65 \mathrm{~V}$, before and after the modification of the surface with AuNPs, in order to record the response of the non-modified BDD and the AuNPs-modified BDD (BDD/APTES/AuNPs) surfaces towards the oxygen reduction reaction (ORR).

\subsection{Preparation of BSA protein fibrils}

Fibril aggregates of BSA were prepared by incubating at $95^{\circ} \mathrm{C}$ for $5 \mathrm{~min}$ an aqueous solution of $5 \mathrm{mg} \mathrm{mL}^{-1}$ of BSA in $1.5 \%$ DMSO. Afterwards, the solution was centrifuged and cleaned with Millipore water in order to remove the DMSO. Prior their deposition on the BDD/APTES/AuNPs for SEIRA-ATR and AFM measurements, the $5 \mathrm{mg} \mathrm{mL}^{-1}$ suspension of fibrils was homogenized via shaking in a Vortex.

\subsection{Protein analysis}

Bovine serum albumin protein was analyzed by using the combined platform with the BDD/APTES/AuNPs ATR crystal at different concentrations of BSA. For measurements, $5 \mu \mathrm{L}$ of the aqueous BSA solution at different concentrations (namely, 1, 2.5 and $5 \mathrm{mg} \mathrm{mL}^{-1}$, which results in an amount of BSA of 5, 12.5 and $25 \mu \mathrm{g}$, respectively) were placed at the BDD/APTES/AuNPs surface and left to dry in air, thus forming a film of protein at the ATR crystal. The same procedure was followed for the analysis of fibrils of protein.

Protein films were characterized with AFM, electrochemistry and IR-ATR spectroscopy. AFM and MIR measurements were performed following the procedure described above (Section 2.2.). Besides, the thickness of the protein film was estimated with AFM by mechanically scratching a section of the film with the AFM tip to remove the biological material and expose the bare BDD surface, 
followed by AFM measurement in intermittent contact mode (experimental details and results are given in the Supporting information). Electrochemical measurements such as square-wave voltammetry (SWV) experiments were obtained in $0.1 \mathrm{M}$ phosphate buffer solution ( $\mathrm{pH} 5.65$ ), between 0.5 and $1.6 \mathrm{~V}$, using following parameters: $0.05 \mathrm{~V}$ amplitude, $5 \mathrm{mV}$ increment and $10 \mathrm{~Hz}$ frequency. All experiments were performed at room temperature $\left(20^{\circ} \mathrm{C}\right)$.

IR data were analyzed using the OPUS 6.5 and PeakFit software packages. SEIRA spectra were analyzed by integrating the area of the protein amide I and amide II bands $\left(1700-1600 \mathrm{~cm}^{-1}\right.$ and $1600-1500 \mathrm{~cm}^{-1}$, respectively). Spectra were smoothed using a 13point Savitzky-Golay algorithm (OPUS 6.5 software package, Bruker Optik). Curve fitting was performed via Gaussian peak-fit model (PeakFit software, Systat Software Inc., San Jose, CA). Firstly, spectra were smoothed with $30 \%$ Fast Fourier Transform (FFT) filtering. FFT filtering removes any linear trend as s a low frequency component; reducing the frequency domain noise for the dataset. The percentage of smoothing defines the breadth of the smoothing. The amide I band $\left(1700-1600 \mathrm{~cm}^{-1}\right)$ of both native and fibrils protein spectrum was analyzed using second derivative and Gaussian peak fitting.

A new SEIRA substrate, formed by the AuNPs attached to the surface via APTES, is prepared before each measurement. Taking into account the low quantities of $\mathrm{HAuCl}_{4}$ needed to prepare the SEIRA substrate, and the fact that the synthesis of the NPs is easy, a new SEIRA substrate is generated prior each measurement to ensure the reproducibility of the measurements. The protein film may interact with the gold nanoparticles via thiol groups of the cysteine residues of BSA, thus, in order to ensure the complete removal of the protein, the crystal was first cleaned with $10 \mathrm{mmol} \mathrm{L}^{-1}$ SDS solution using optical cleaning tissues and $40 \%$ (v/v) $\mathrm{NH}_{4} \mathrm{~F}$ solution, and further submitted to $\mathrm{HCl}$ and $\mathrm{H}_{2} \mathrm{SO}_{4}$ electrochemical treatment to complete remove the AuNPs at the surface. The AuNPs were re-dissolved in $0.1 \mathrm{M} \mathrm{HCl}$ by cycling the BDD ATR electrode between 0 and $1.5 \mathrm{~V}, 1.5$ and $0.8 \mathrm{~V}, 0.8-1.5 \mathrm{~V}$, $1.5-0.8 \mathrm{~V}$ and 0.8 and $2 \mathrm{~V}$ versus $\mathrm{Ag} / \mathrm{AgCl}$ at $0.1 \mathrm{~V} \mathrm{~s}^{-1}$. In order to activate the oxygen groups at the surface the ATR crystal was cycled 20 times between 0 and $2.5 \mathrm{~V}$ at $0.1 \mathrm{~V} \mathrm{~s}^{-1}$, as previously described for the amino functionalization of the BDD surface.

\section{Results and discussion}

\subsection{Characterization of the surface modification}

The BDD IR-transparent electrode was amino-terminated via silanization with APTES. Firstly, the BDD-modified ATR crystal was cycled in $0.1 \mathrm{M}$ sulfuric acid aqueous solution in order to obtain an oxygen-terminated surface. Such oxygen-terminated BDD surfaces are characterized by oxygen-containing functional groups, mainly consisting of hydroxyl $(-\mathrm{OH})$, carbonyl $(=\mathrm{O})$ and ether $\left(-\mathrm{O}_{-}\right)$ groups. However, only the - $\mathrm{OH}$ termination will preferably react with the silane groups of the APTES. Therefore, the BDD ITE was treated in a further step with a $\mathrm{KOH}$ solution for converting the oxygen-termination into $-\mathrm{OH}$ groups. The generated hydroxyl groups were chemically modified with APTES, rendering an aminoterminated BDD surface for further binding of in-situ synthesized gold nanoparticles. Surface modification of BDD with the silane coupling agent was confirmed by AFM, as displayed in Fig. 1. Fig. $1 \mathrm{~A}$ shows the unmodified BDD surface, in which the polishing lines of the homoepitactically BDD-modified diamond ATR surface are visible. After APTES modification, an increase in surface roughness was observed, from $0.455 \pm 0.137 \mathrm{~nm}$ of the non-modified BDD surface but after $\mathrm{H}_{2} \mathrm{SO}_{4}$ and $\mathrm{KOH}$ treatment to $0.620 \pm 0.068 \mathrm{~nm}$ of the APTES-coated crystal, respectively.
Next, AuNPs were synthesized from a tetrachloroauric acid solution mediated by a stainless steel O-ring. As AuNPs were formed in solution, they precipitated onto the BDD surface forming a sub-monolayer coverage of nanoparticles, with some larger aggregates evident in the correspondingly obtained AFM images (Fig. 1C). For an estimation of the size distribution, only features larger than $10 \mathrm{~nm}$ in height were considered to avoid that possible APTES agglomerates may be confused with AuNPs. The size distribution of the AuNPs was estimated to follow a Gaussian-type distribution (Fig. 1D), finding an average value of around $23 \mathrm{~nm}$, similarly to that already previously shown [20]. Most of the particles have a height distribution of $10-30 \mathrm{~nm}$, whereas features over 40-50 nm height seem to correspond to aggregates of AuNPs.

The evolution of the synthesis and adsorption of AuNPs on the APTES-treated BDD surface was also evaluated via SEIRA effect, and quantified by determining the area of the $\delta_{W}$ bending vibration band at $1644 \mathrm{~cm}^{-1}$. As gold nanoparticles were synthesized and deposited within the evanescent field, an enhancement in the water absorption features was observed, despite the effective decrease of water molecules present within the evanescent field, being displaced by AuNPs. Such enhancement was attributed to the SEIRA effect produced by the AuNPs [19,42]. SEIRA was also induced in the even stronger absorptive $\nu_{\mathrm{W}}$ stretching mode, at around $3200 \mathrm{~cm}^{-1}$. However, the possible adsorption/desorption of hydroxyl groups at the native BDD surface exposed to aqueous solution would also alter the IR response in this spectral region [43], thus rendering the $\delta_{W}$ mode more reliable for the clear distinction of the enhancement effect solely induced in water.

The synthesis of the AuNPs showed a clear tendency in repeated experiments, as deduced from the displayed data and error bars in Fig. 2B. Unfortunately, high reproducibility was not found in the accurate integral values of the enhanced bands. The resulting SEIRA effect is mainly dependent on two influential factors, namely the temperature of the solution (since it affects the movement of the formed particles towards the diamond surface), and most important the state of the metal ring (presence of smooth surface or surface already containing corroding pits, scratches, etc.). Although control could be established for the former factor, the stainless steel o-rings used were not provided with the same surface appearance, yet polishing with $\mathrm{SiC}$ paper was always conducted in order to maintain a repetitive response in different measurements. Moreover, the proposed mechanism for this synthesis, as reported previously [20], has involved a redox reaction in which iron is oxidized and released as metal cations. That is, a pitting corrosion phenomenon (either propagating pitting or metastable pitting), which may be stochastic in nature, is responsible for the synthesis. This adds more uncertainty to any chemical process eventually dependent on that process.

The time for the surface functionalization with both - APTES and AuNPs - was optimized. 5 min of contact with the APTES solution was found to be sufficient for the formation of a monolayer of APTES. As displayed in Fig. 2, the synthesis of AuNPs within a period of 20 min still shows a continues increase of the water bending band, which is associated with AuNPs being attached into the surface. After deposition times of AuNPs $>20$ min small aggregates of AuNPs appeared; whereas, as previously demonstrated [19], at longer times ( $>100 \mathrm{~min}$ ) islands together with significant agglomerates of NPs were observed, along with no further increase of the water absorption features. Hence, for all further measurements, a synthesis time of 15 min was selected, as a compromise between sensitivity and avoiding the formation of AuNPs clusters, which would obstruct the distinction of the individual proteins or the protein films in the AFM measurements.

The modification of the BDD-modified ATR crystal with gold nanoparticles was further characterized via the electrochemical response towards the oxygen reduction reaction (ORR) of dissolved 

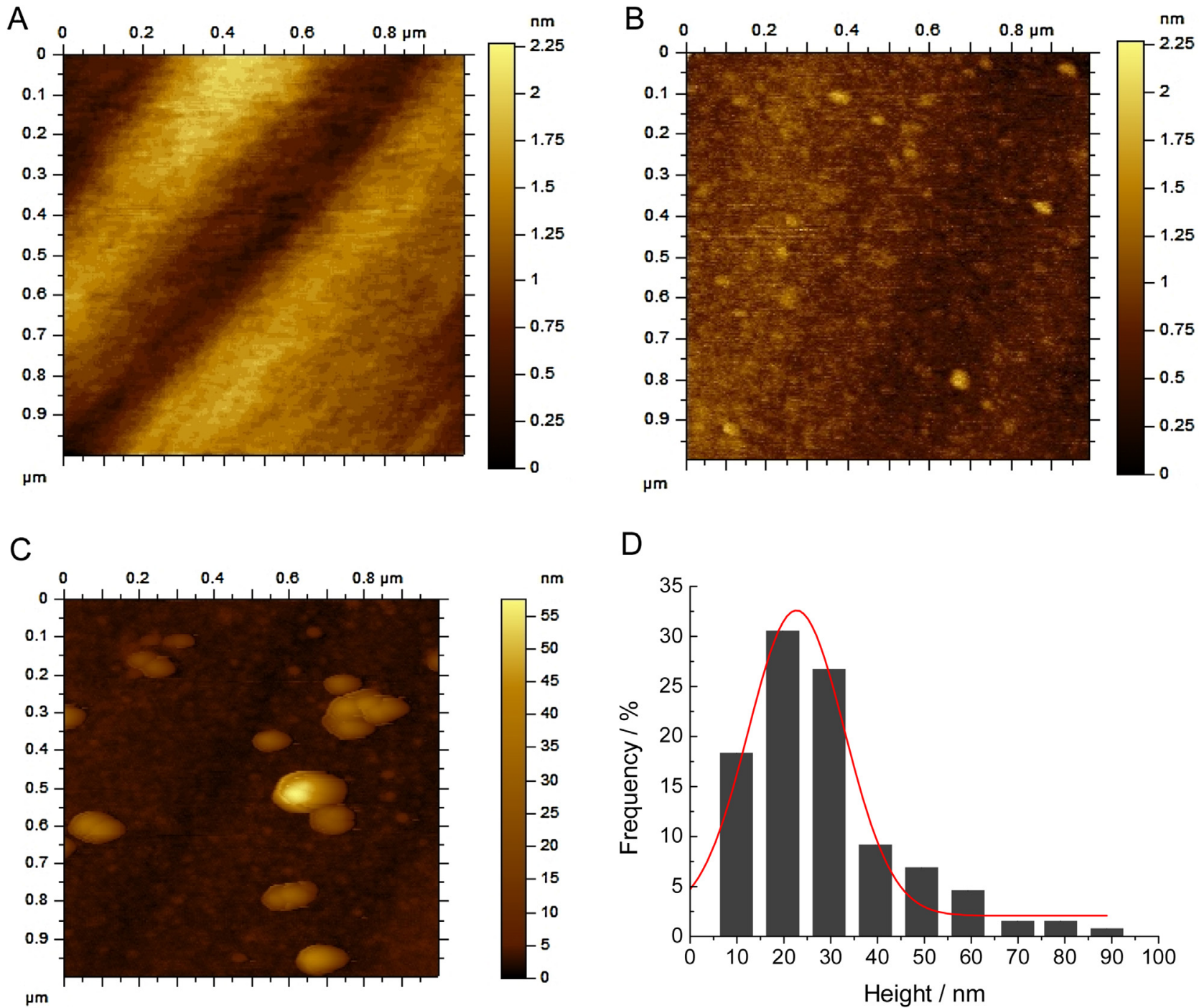

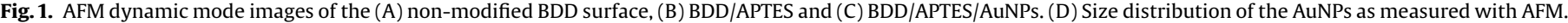
Scan rate: $0.7 \mu \mathrm{m} \mathrm{s}^{-1}$, setpoint $85 \%$ of the amplitude vibration of the tip before approaching to the surface.
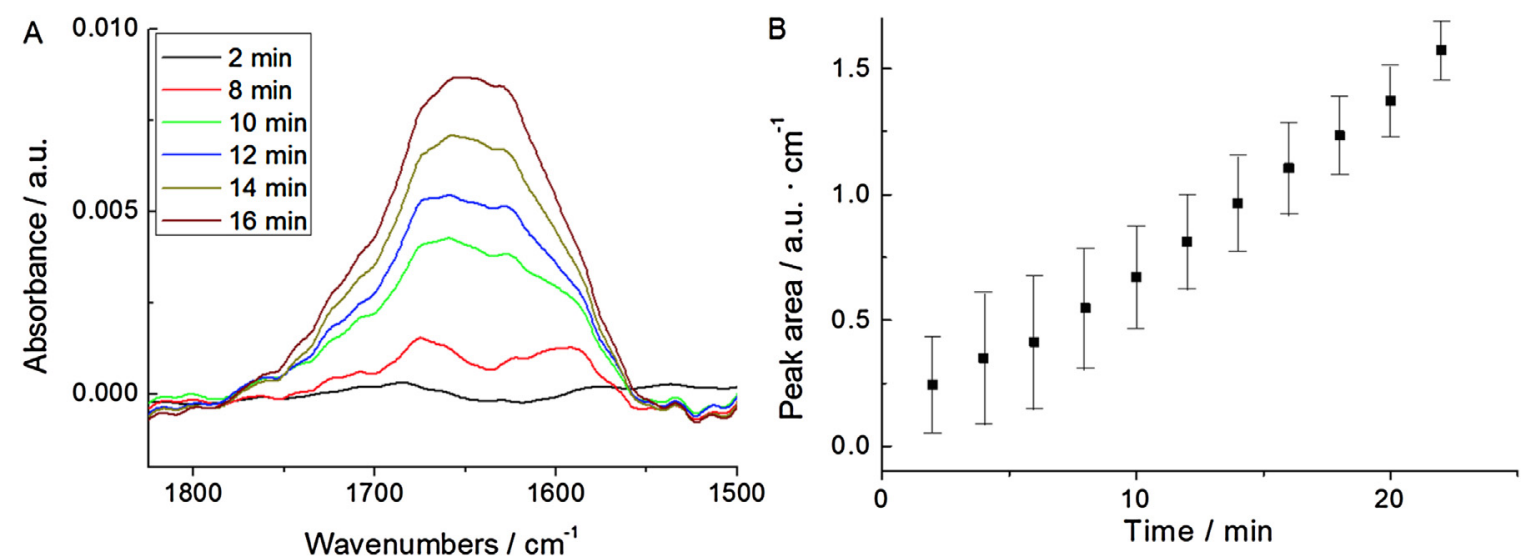

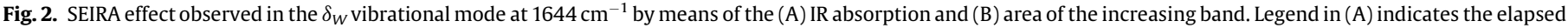

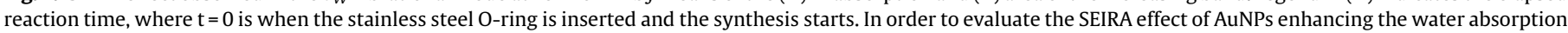

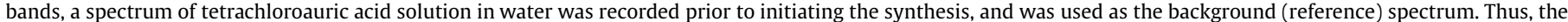

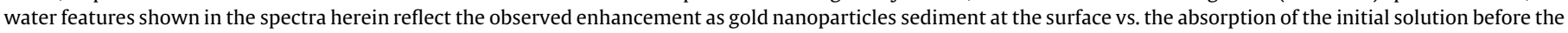
formation of the AuNPs.

Please cite this article in press as: A.I. López-Lorente, et al., Boron-doped diamond modified with gold nanoparticles for the characterization of bovine serum albumin protein, Vib. Spectrosc. (2016), http://dx.doi.org/10.1016/j.vibspec.2016.10.010 


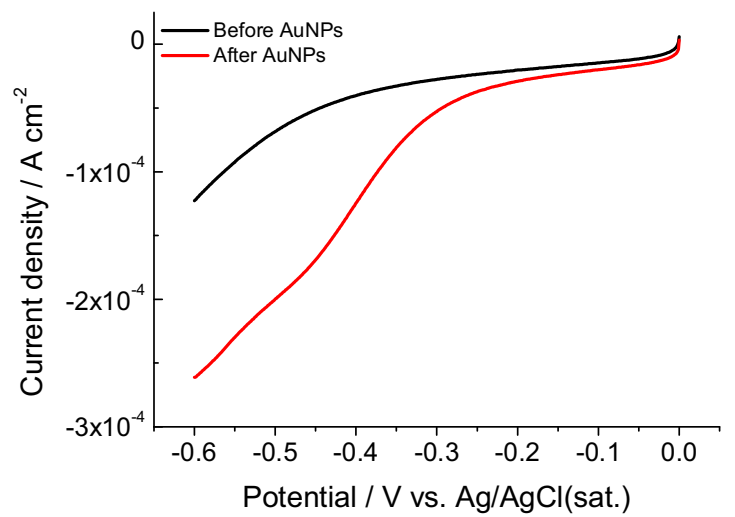

Fig. 3. LSV obtained before and after the modification of the BDD/APTES-modified ATR crystal with AuNPs in $0.1 \mathrm{M}$ phosphate buffer solution ( $\mathrm{pH}$ 5.65) depicting the oxygen electro-reduction wave.

oxygen in phosphate buffer solution, as shown in Fig. 3. BDD is known to exhibit a high overpotential for the ORR, thus resulting in wider potential windows when compared with noble metal basedelectrodes [24]. The modification with AuNPs resulted in significant increase of the cathodic current at potentials more negative than $-0.25 \mathrm{~V}$ as a consequence of the induced catalysis in ORR.

\subsection{Surface enhanced infrared absorption spectroscopy on BSA}

BSA proteins were analyzed in the dried state via SEIRAS after the deposition of $5 \mu \mathrm{L}$ of an aqueous BSA solution at different concentrations (namely, $1,2.5$ and $5 \mathrm{mg} \mathrm{mL}^{-1}$, which results in an amount of BSA of 5, 12.5 and $25 \mu \mathrm{g}$, respectively) at the BDD/ APTES/AuNPs ATR crystal. The thickness of the protein film was estimated to be $450 \mathrm{~nm}$ for the highest amount of protein, as estimated from the AFM experiments detailed in the Supporting information. This film was approximately 1.6 -fold thicker than that formed with the half amount of BSA (12.5 instead of $25 \mu \mathrm{g}$ ), suggesting higher protein density with larger amounts of BSA. It has to be pointed out that in every condition the deposited protein laid within the penetration depth of the evanescent field, in spite of the presence of the nanoparticles.

The IR spectra of BSA protein is characterized by the amide I and amide II bands, which appear at $1700-1600 \mathrm{~cm}^{-1}$ and $1600-$ $1500 \mathrm{~cm}^{-1}$, respectively. The band at $1652 \mathrm{~cm}^{-1}$ is ascribed to the amide I vibration ( $\mathrm{C}=\mathrm{O}$ stretching), while the amide II band, at
$1530 \mathrm{~cm}^{-1}$, is associated with the $\mathrm{N}-\mathrm{H}$ stretching vibration along with $\mathrm{C}-\mathrm{N}$ and $\mathrm{C}=\mathrm{C}$ stretching vibrations [44].

It could be observed that an increase in IR signal was not only obtained in dependence of the protein concentration, resulting in approximately twice the absorption signal at $5.0 \mathrm{mg} \mathrm{mL}^{-1}(25 \mu \mathrm{g}$ of BSA deposited) in comparison to $2.5 \mathrm{mg} \mathrm{mL}^{-1}$ (which results in the deposition of $12.5 \mu \mathrm{g}$ ). As shown in Fig. 4, the presence of the AuNPs layer also leads to an enhancement of the IR signal, i.e. the amide II band intensity obtained for $2.5 \mathrm{mg} \mathrm{mL}^{-1} \mathrm{BSA}$ protein at the BDD/APTES/AuNPs surface being similar to that of $5.0 \mathrm{mg} \mathrm{mL}^{-1}$ measured at the non-modified BDD substrate.

The areas of both amide I and amide II bands were evaluated at the non-modfied BDD as well as at the BDD/APTES/AuNPs surface. The presence of AuNPs within the evanescent field leads to an enhancement in the area of the amide I band of $\sim 1.8$ times, and $\sim 2.4$ times for the amide II band area, for a concentration of BSA of $2.5 \mathrm{mg} \mathrm{mL}^{-1}(12.5 \mu \mathrm{g})$. Similar enhancement was found for $5.0 \mathrm{mg} \mathrm{mL}^{-1}(25 \mu \mathrm{g})$. Nevertheless, considering the average size of the nanoparticles ( $23 \mathrm{~nm}$ ) and agglomerates (up to $90 \mathrm{~nm}$ ), and the thickness of the protein film, the enhancement factor expected would be lower than in the case of thinner films since the SEIRA effect is reported to have influence only within the few nanometers in proximity to the AuNPs. The observed enhancement could be explained on the basis of the fact that although the amount of BSA protein has been increased twice, the thickness of the film is only 1.6-fold, which suggests a higher density of BSA molecules also present in the vicinity of the gold nanoparticles, contributing to the observed enhancement. In the case of the use of this methodology for quantification purposes, the mechanisms leading to the enhancement should be investigated in more detail. The strong interaction between the exposed thiol groups of the cysteine residues of the BSA and the AuNPs probably plays a crucial role in this signal enhancement, as the SEIRA effect is based not only on electromagnetic but also on chemical interactions [45]. Conversely, in the absence of AuNPs it was not possible to distinguish the IR spectrum of proteins formed from $1.0 \mathrm{mg} \mathrm{mL}^{-1}$ solution $(5 \mu \mathrm{g})$ from the background noise, thus, the enhancement factor obtained in such conditions could not be calculated. It would be expected that the enhancement observed for protein monolayers of a few nanometers was higher. However, since the combined set up comprises a single bounce ATR crystal, the sensitivity provided is not enough to evaluate it. Nevertheless, as can be seen in Fig. 4, the signal obtained for amide II band of $2.5 \mathrm{mg} \mathrm{mL}^{-1}$ BSA deposited on the SEIRA substrate is similar to that observed for $5.0 \mathrm{mg} \mathrm{mL}^{-1}$ on the non-modified BDD. This clearly illustrates the advantages of
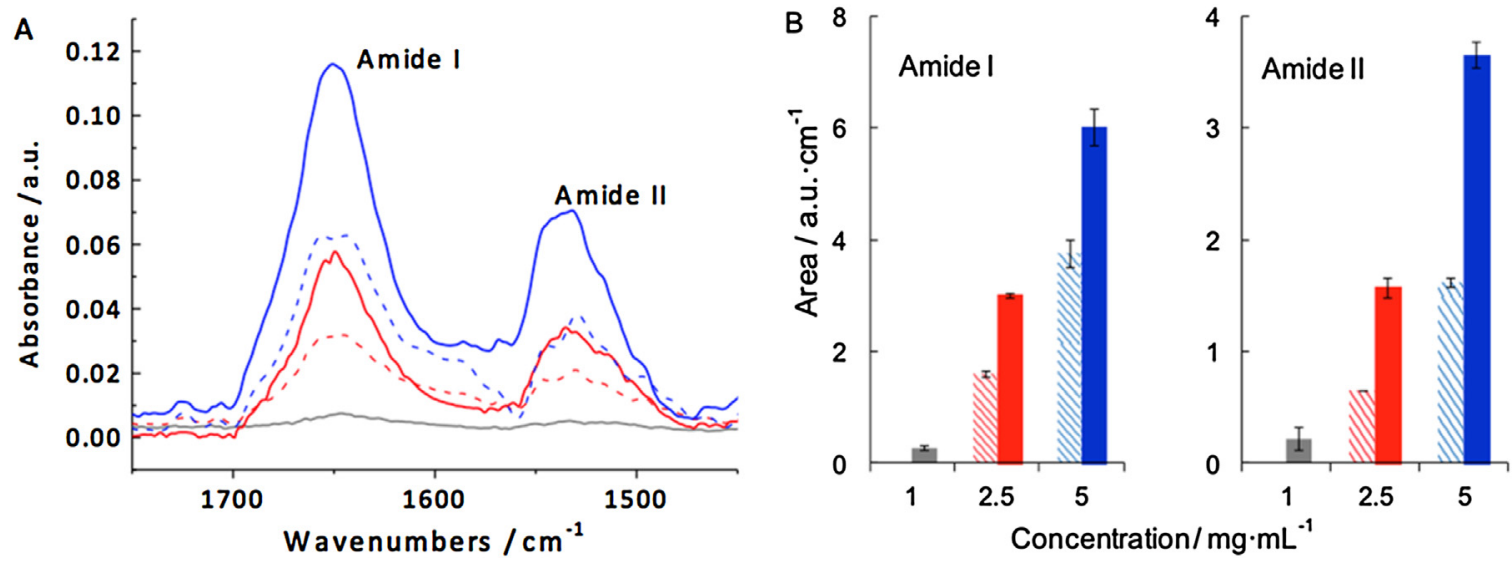

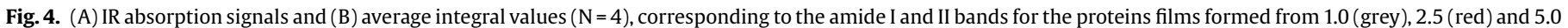

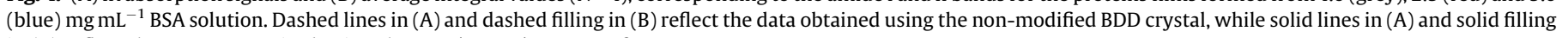
in (B) reflect the spectra acquired using the BDD/APTES/AuNPs surface. 
the modification with AuNPs for the spectroscopic evaluation of proteins.

\subsection{AFM and electrochemical characterization of BSA at non-modified $B D D$ and BDD/APTES/AuNPs surface}

The deposition of $5 \mu \mathrm{L}$ BSA at the BDD crystal resulted in the formation of a protein film for concentrations of 2.5 and $5.0 \mathrm{mg} \mathrm{mL}^{-1}$, as clearly visible in the AFM images shown in Fig. 5A-C. Such films appear rather homogeneous when formed at the non-modified BDD surface (cf. Fig. 5A), whereas the AuNPs and their aggregates present at the modified crystal promoted the appearance of inhomogeneities of the protein layer (cf. Fig. 5B, C). No film was encountered at the BDD/APTES/AuNPs electrode for the deposition of BSA with the lowest concentration of $1.0 \mathrm{mg}$ $\mathrm{mL}^{-1}$. In addition, the agglomerates of AuNPs could not be easily distinguished from individual and agglomerates of globular BSA, as shown in Fig. 5D.

Preliminary electrochemical experiments performed via SWV also showed that BSA films may be indirectly characterized by electrochemistry using the oxidation behavior of the AuNPs in phosphate buffer solution. Results are given in Fig. 6 in the absence and presence of BSA and AuNPs. An oxidation signal at $0.92 \mathrm{~V}$ was only observed when the experiment was performed in the absence of AuNPs (inset in Fig. 6). This may be attributed to the direct

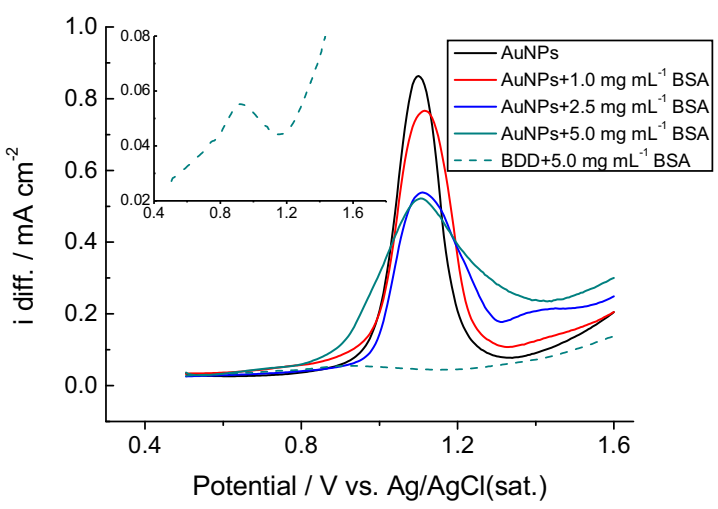

Fig. 6. SWV signal obtained in phosphate buffer solution. Legend gives the concentration of the BSA solution used for protein deposition at the non-modified BDD or the surface modified with AuNPs. Inset gives the magnified signal for the non-modified BDD surface with protein film formed from $5.0 \mathrm{mg} \mathrm{mL}^{-1} \mathrm{BSA}$ solution.

oxidation of the BSA, which has been shown to be irreversible and favored at BDD electrodes when compared with glassy carbon or platinum electrodes [26]. The oxidation of BSA is highly dependent on the surface termination of the doped diamond crystal, as well as the $\mathrm{pH}$ of the solution. Distinct anodic peaks were found in the presence of AuNPs at $1.11 \mathrm{~V}$, reflecting the oxidation of the gold
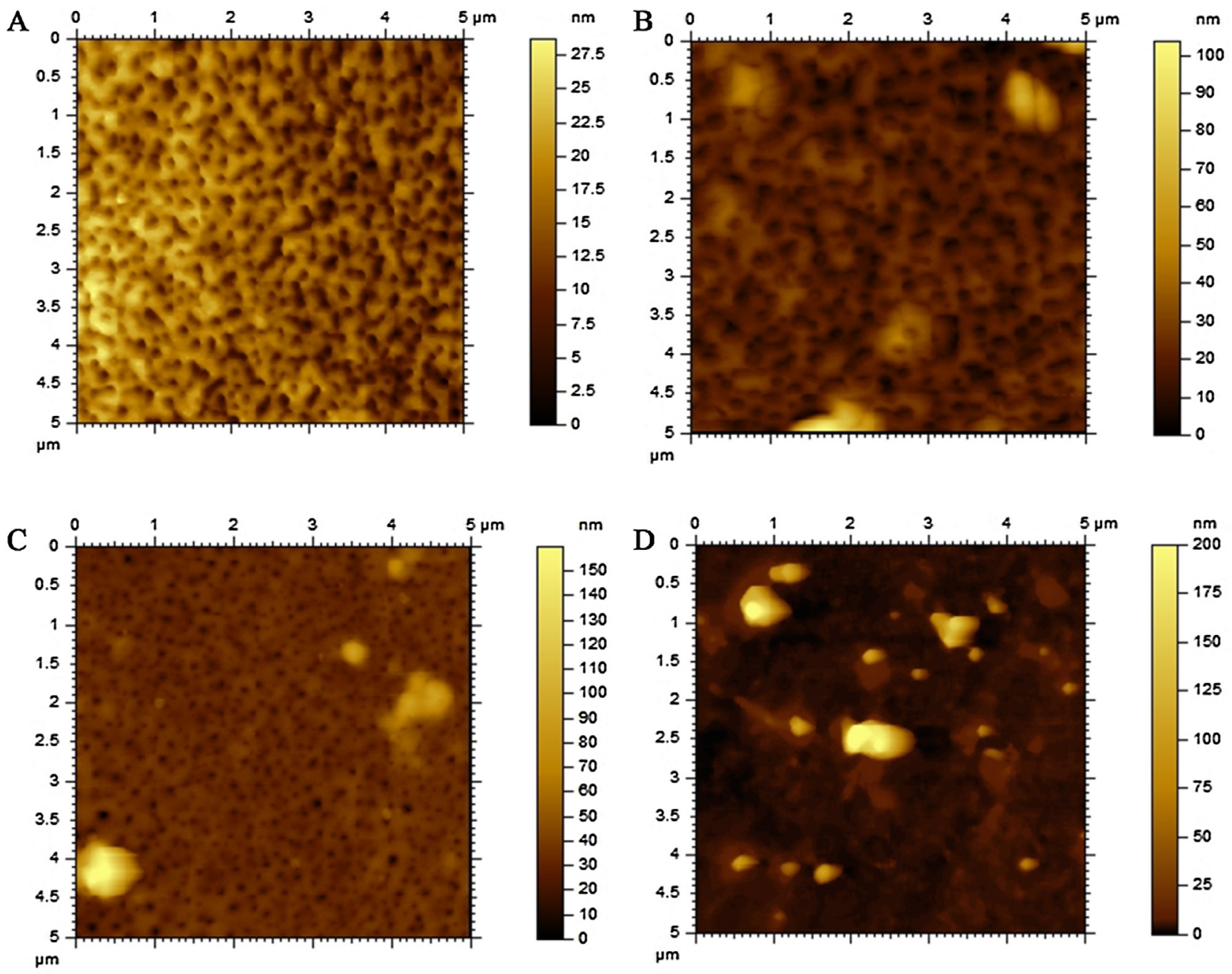

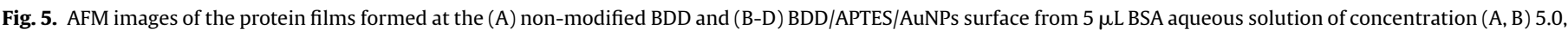
(C) 2.5 and (D) $1.0 \mathrm{mg} \mathrm{mL}^{-1}$. Scan rate: $2 \mu \mathrm{m} \mathrm{s}^{-1}$, setpoint $85 \%$ of the amplitude vibration of the tip before approaching to the surface.

Please cite this article in press as: A.I. López-Lorente, et al., Boron-doped diamond modified with gold nanoparticles for the characterization of bovine serum albumin protein, Vib. Spectrosc. (2016), http://dx.doi.org/10.1016/j.vibspec.2016.10.010 

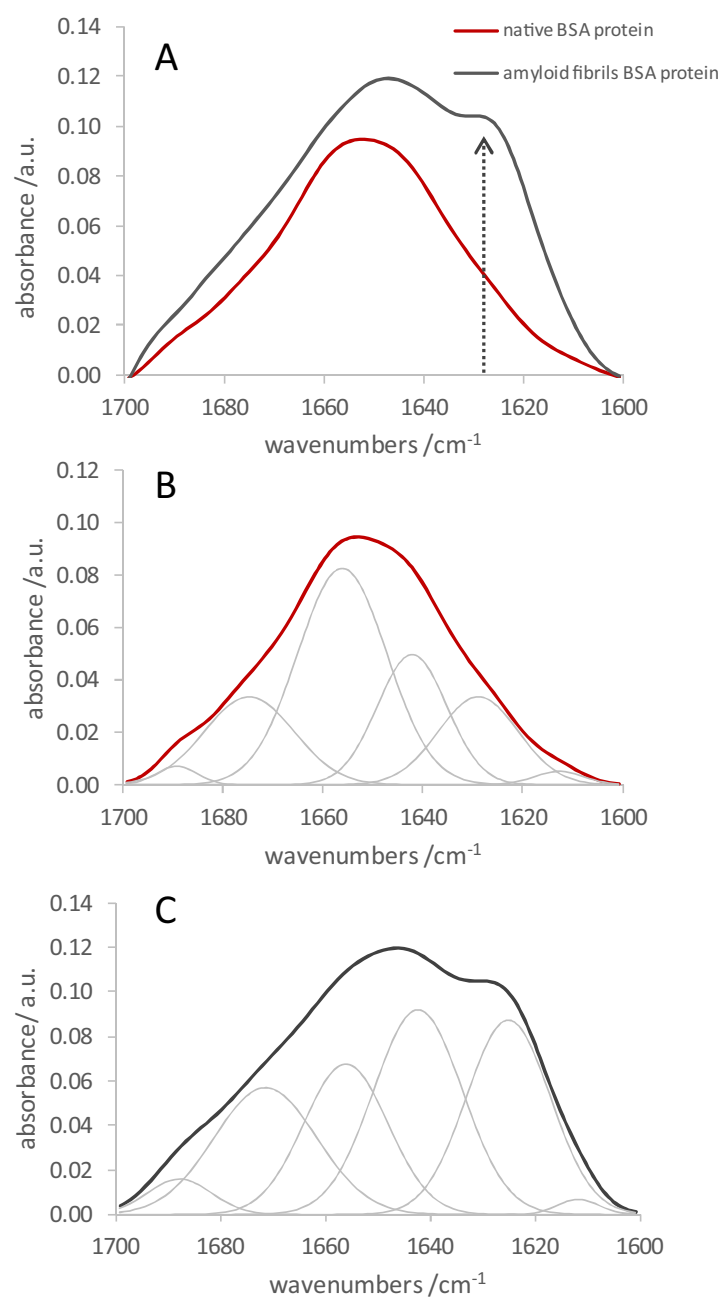

Fig. 7. (A) IR spectra in the amide I region of native and amyloid fibrils BSA protein, (B) Curve fitting of amide I band of native BSA protein IR spectrum (protein concentration $5.0 \mathrm{mg} \mathrm{mL}^{-1}$ ), (C) curve fitting of amyloid fibrils of BSA protein (protein concentration $5.0 \mathrm{mg} \mathrm{mL}^{-1}$ ).

nanoparticles [29]. A general trend of reduced peak currents in correlation with the adsorption of BSA with increasing concentration of protein could be observed, as BSA inhibits the oxidation of the AuNPs [46]. Similar inhibition effects have been exploited in literature for calibration purposes of other biomolecules adsorbed on AuNPs [29]. The chemical interaction between the AuNPs and the BSA also seems to determine the peak shape. In this sense, tailing current signals are observed at potentials more positive than the peak position oxidation potential of AuNPs, resulting in a broad current signal in the $1.2-1.6 \mathrm{~V}$ region being higher with increased amount of adsorbed protein (cf. Fig. 6). It appears that higher applied potentials are needed for the complete oxidation of the AuNPs when more protein is present. Besides, the onset shows that the oxidation peak signal at the BSA-modified AuNPs formed from $5.0 \mathrm{mg} \mathrm{mL}^{-1}$ arises at lower potentials $(\sim 0.85 \mathrm{~V})$ as compared with the other depicted AuNPs-containing systems in Fig. $6(\sim 1 \mathrm{~V})$, probably due to the contribution of the oxidation of the protein itself in the overall current signal. Such electrochemical behavior will be further investigated in the future, studying in depth all the parameters influencing the signal such as the synthesis and deposition of the AuNPs at the BDD electrode, etc., since the size distribution and aggregation state of the nanoparticles may affect the reproducibility of the measurements. Interestingly, cyclic voltammetry experiments performed at the AuNP-modified BDD and a gold macro disc-electrode showed that the macroscopic electrode revealed sufficient reproducibility, which suggests the effect of size and surface coverage in case of the nanostructurefunctionalized BDD electrode surface.

\subsection{Investigation of BSA fibrils formation}

BSA is a globular protein, whose secondary structure is mainly dominated by $\alpha$-helices. Fig. 7B shows the curve fitting of the amide I band of native BSA protein spectrum (from the $5 \mathrm{mg} \mathrm{mL}^{-1}$ solution), fitted by Gaussian peaks with a coefficient of determination $r^{2}>0.9997$. This region is characterized by the presence of peaks around $1655 \mathrm{~cm}^{-1}$, due to the main contribution of $\alpha$-helix structures. According to literature [9], the bands revealed by the fitting curves can be assigned to the different secondary structures of BSA protein. As previously mentioned, the spectrum is dominated by a band at around $1655 \mathrm{~cm}^{-1}$, which is assigned to the $\alpha$-helix secondary structure. The band at around $1612 \mathrm{~cm}^{-1} \mathrm{can}$ be assigned to intermolecular $\beta$-sheet structures as well as that at around $1628 \mathrm{~cm}^{-1}$, which has been attributed in literature both to intramolecular $\beta$-sheet [47] or with short segments chains connecting $\alpha$-helix segments [48]. On the other hand, the band at around $1642 \mathrm{~cm}^{-1}$ reflects random coils, and those at $1674 \mathrm{~cm}^{-1}$ and $1689 \mathrm{~cm}^{-1}$ can be ascribed to $\beta$-turns [9].

\section{A}

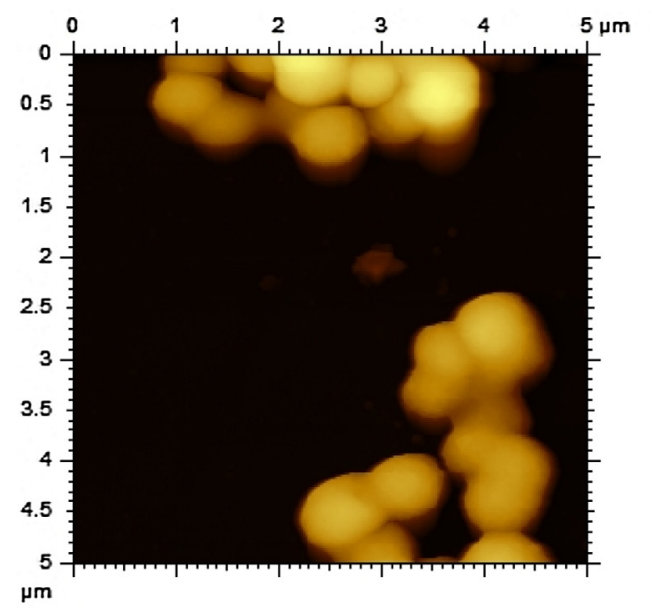

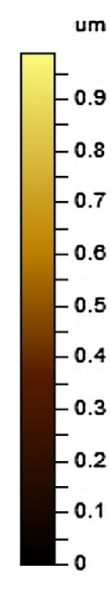

B

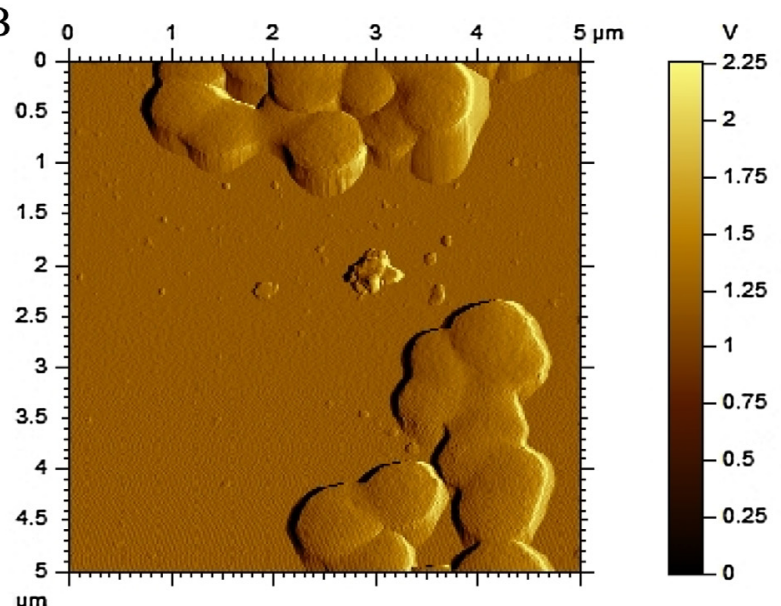

Fig. 8. AFM images of the fibril aggregates of BSA formed from $1.0 \mathrm{mg} \mathrm{mL}^{-1}$ aqueous solution; (A) topography and (B) amplitude.

Please cite this article in press as: A.I. López-Lorente, et al., Boron-doped diamond modified with gold nanoparticles for the characterization of bovine serum albumin protein, Vib. Spectrosc. (2016), http://dx.doi.org/10.1016/j.vibspec.2016.10.010 
Fibril aggregates of BSA protein were induced via heating of the protein aqueous solution in the presence of DMSO. A feature of protein aggregation is the increase of crossed $\beta$-sheet structures within the secondary structure of the proteins. As shown in Fig. 7A and $C$, the formation of fibrils of BSA leads to differences within the amide I region of the spectrum of the protein. As can be seen, after curve fitting of the amide I band of the fibrils $\left(\mathrm{r}^{2}>0.9995\right)$, there is an increase of the sub-peak at approximately $1625 \mathrm{~cm}^{-1}$, whose sub-peak area increases from $15.68 \%$ to $25.78 \%$, according to the presence of intermolecular crossed $\beta$-sheet structures. It should be noted that there is also an increase in the relative contribution of the band at around $1642 \mathrm{~cm}^{-1}$, which is associated with the formation of a random coil of BSA. Measurements were performed on $5 \mu \mathrm{L}$ of a $5 \mathrm{mg} \mathrm{mL}^{-1}$ solution after drying onto the modified ATR crystal.

Complementarily to MIR spectroscopic measurements, the formation of amyloid fibril aggregates of BSA protein was also evaluated via AFM. Fig. 8 shows AFM images of the BDD/APTES/ AuNPs crystal with deposited fibrillated BSA protein. The topography is presented in Fig. 8A and the amplitude in Fig. 8B, respectively. From comparison of Fig. 8 with Fig. 5D, the deposition of fibril BSA results in features depicting the appearance of aggregates with height values up to approx. $900 \mathrm{~nm}$ (cf. Fig. 8A) along with smaller features which have been attributed to AuNPs at the surface of the ITE (cf. Fig. 8B).

\section{Conclusions}

Boron-doped diamond ITE modified with AuNPs (BDD/APTES/ AuNPs) has been examined as multi-analytical platform for the characterization of BSA protein films using spectroscopic, electrochemical methods and AFM imaging. The deposition of the AuNPs, synthesized by a stainless steel assisted method, was monitored and optimized taking advantage of the SEIRA effect induced in the water molecules. After modification, the adsorption of BSA at the $\mathrm{BDD} / \mathrm{APTES} / \mathrm{AuNPs}$ resulted in IR bands for the amide I and amide II absorption with twice the area of the signals measured using the non-modified BDD, which facilitated the distinction of $\beta$-sheet structures characteristics of amyloid fibrils and fibril aggregates. The fibrillation method herein employed resulted in the formation of aggregates, rather than individual fibrils, as deduced from the AFM images. Finally, the potential of the platform for electrochemical characterization of the protein films was preliminary investigated by square-wave voltammetry taking advantage of the interaction between BSA and AuNPs, observing a decrease in the current associated with the oxidative dissolution of the nanoparticles.

\section{Conflict of interest}

The authors declare no competing financial interest.

\section{Acknowledgments}

A.I. López-Lorente and J. Izquierdo thank the Alexander von Humboldt Foundation for the award of a Postdoctoral Fellowship. Funding by the Horizon 2020 Framework Program of the European Union within the MSCA RISE Project TROPSENSE is also acknowledged.

\section{Appendix A. Supplementary data}

Supplementary data associated with this article can be found, in
the online version, at http://dx.doi.org/10.1016/j.
vibspec.2016.10.010.

\section{References}

[1] A.I. López-Lorente, B. Mizaikoff, Mid-infrared spectroscopy for protein analysis: potential and challenges, Anal. Bioanal. Chem. 408 (2016) 28752889, doi:http://dx.doi.org/10.1007/s00216-016-9375-5.

[2] A. Barth, Infrared spectroscopy of proteins, Biochim. Biophys. Acta-Bioenergy 1767 (2007) 1073-1101, doi:http://dx.doi.org/10.1016/j.bbabio.2007.06.004.

[3] Y. Shai, ATR-FTIR studies in pore forming and membrane induced fusion peptides, Biochim. Biophys. Acta-Biomembr. 1828 (2013) 2306-2313, doi: http://dx.doi.org/10.1016/j.bbamem.2012.11.027.

[4] A. Blume, A. Kerth, Peptide and protein binding to lipid monolayers studied by FT-IRRA spectroscopy, Biochim. Biophys. Acta - Biomembr. 1828 (2013) 22942305, doi:http://dx.doi.org/10.1016/j.bbamem.2013.04.014.

[5] R. Mendelsohn, G. Mao, C.R. Flach, Infrared reflection-absorption spectroscopy: principles and applications to lipid-protein interaction in Langmuir films, Biochim. Biophys. Acta - Biomembr. 1798 (2010) 788-800, doi:http://dx.doi.org/10.1016/j.bbamem.2009.11.024.

[6] C. Liang, Catching protein structural dynamics by two-dimensional infrared spectroscopy, Biophys. J. 108 (2015) 1577-1579, doi:http://dx.doi.org/10.1016/ j.bpj.2015.03.007.

[7] C.R. Baiz, C.S. Peng, M.E. Reppert, K.C. Jones, A. Tokmakoff, Coherent twodimensional infrared spectroscopy: quantitative analysis of protein secondary structure in solution, Analyst 137 (2012) 1793-1799, doi:http://dx.doi.org/ 10.1039/c2an16031e.

[8] V.A. Lórenz-Fonfría, M. Granell, X. León, G. Leblanc, E. Padro, In-plane and outof-plane infrared difference spectroscopy unravels tilting of helices and structural changes in a membrane protein upon substrate binding, J. Am. Chem. Soc. 131 (2009) 15094-15095, doi:http://dx.doi.org/10.1021/ja906324z.

[9] R. Lu, W.-W. Li, A. Katzir, Y. Raichlin, H.-Q. Yu, B. Mizaikoff, Probing the secondary structure of bovine serum albumin during heat-induced denaturation using mid-infrared fiberoptic sensors, Analyst 140 (2015) 765770, doi:http://dx.doi.org/10.1039/c4an01495b.

[10] Y. Yokoyama, R. Ishiguro, H. Maeda, M. Mukaiyama, K. Kameyama, K. Hiramatsu, Quantitative analysis of protein adsorption on a planar surface by Fourier transform infrared spectroscopy: lysozyme adsorbed on hydrophobic silicon-containing polymer, J. Colloid Interface Sci. 268 (2003) 23-32, doi:http://dx.doi.org/10.1016/j.jcis.2003.07.011.

[11] S.A. Tatulian, Attenuated total reflection fourier transform infrared spectroscopy: a method of choice for studying membrane proteins and lipids, Biochemistry 42 (2003) 11898-11907, doi:http://dx.doi.org/10.1021/ bi034235+.

[12] P. Wang, W. Bohr, M. Otto, K.M. Danzer, B. Mizaikoff, Quantifying amyloid fibrils in protein mixtures via infrared attenuated-total-reflection spectroscopy, Anal. Bioanal. Chem. 407 (2015) 4015-4021, doi:http://dx.doi. org/10.1007/s00216-015-8623-4.

[13] E. Maltseva, G. Brezesinski, Adsorption of amyloid beta (1-40) peptide to phosphatidylethanolamine monolayers, ChemPhysChem 5 (2004) 1185-1190, doi:http://dx.doi.org/10.1002/cphc.200400045.

[14] A. Nabers, J. Ollesch, J. Schartner, C. Kötting, J. Genius, U. Haußmann, H. Klafki, J. Wiltfang, K. Gerwert, An infrared sensor analysing label-free the secondary structure of the Abeta peptide in presence of complex fluids, J. Biophotonics 9 (2016) 224-234, doi:http://dx.doi.org/10.1002/jbio.201400145.

[15] R. Sarroukh, E. Goormaghtigh, J.M. Ruysschaert, V. Raussens, ATR-FTIR: a "rejuvenated" tool to investigate amyloid proteins, Biochim. Biophys. Acta Biomembr. 1828 (2013) 2328-2338, doi:http://dx.doi.org/10.1016/j. bbamem.2013.04.012.

[16] C. Paul, P.H. Axelsen, $\beta$-sheet structure in amyloid $\beta$ fibrils and vibrational dipolar coupling, J. Am. Chem. Soc. 127 (2005) 5754-5755, doi:http://dx.doi. org/10.1021/ja042569w.

[17] B. Jin, W.-J. Bao, Z.-Q. Wu, X.-H. Xia, In situ monitoring of protein adsorption on a nanoparticulated gold film by attenuated total reflection surface-enhanced infrared absorption spectroscopy, Langmuir 28 (2012) 9460-9465, doi:http:// dx.doi.org/10.1039/c2cc17058b.

[18] F. Le, D.W. Brandl, Y.A. Urzhumov, H. Wang, J. Kundu, N.J. Halas, J. Aizpurua, P. Nordlander, Metallic nanoparticle arrays: a common substrate for both surface-enhanced Raman scattering and surface-enhanced infrared absorption, ACS Nano 2 (2008) 707-718, doi:http://dx.doi.org/10.1021/ nn800047e.

[19] A.I. López-Lorente, M. Sieger, M. Valca'rcel, B. Mizaikoff, Infrared attenuated total reflection spectroscopy for the characterization of gold nanoparticles in solution, Anal. Chem. 86 (2014) 783-789, doi:http://dx.doi.org/10.1021/ ac403284f.

[20] A.I. López-Lorente, B.M. Simonet, M. Valcárcel, S. Eppler, R. Schindl, C. Kranz, B. Mizaikoff, Characterization of stainless steel assisted bare gold nanoparticles and their analytical potential, Talanta 118 (2014) 321-327, doi:http://dx.doi. org/10.1016/j.talanta.2013.10.028.

[21] A.I. López-Lorente, M. Valcárcel, B. Mizaikoff, Continuous flow synthesis and characterization of tailor-made bare gold nanoparticles for use in SERS, Microchim. Acta 181 (2014) 1101-1108, doi:http://dx.doi.org/10.1007/s00604014-1215-8.

[22] S. Tomljenovic-Hanic, T.J. Karle, A.D. Greentree, B.C. Gibson, B.A. Fairchild, A. Stacey, S. Prawer, Diamond-based optical waveguides, cavities, and other microstructures, in: R.P. Mildren, J.R. Rabeau (Eds.), Optical Engineering of Diamond, 1st edition, Wiley-VCH Verlag GmbH \& Co. KGaA, Weinheim, 
G Model

VIBSPE 2648 No. of Pages 10

10

A.I. López-Lorente et al./Vibrational Spectroscopy $x x x$ (2016) $x x x-x x x$

Germany, 2013, pp. 311-351, doi:http://dx.doi.org/10.1002/9783527648603. ch10.

[23] P. Achatz, J.A. Garrido, M. Stutzmann, O.A. Williams, D.M. Gruen, A. Kromka, D. Steinmüller, Optical properties of nanocrystalline diamond thin films, Appl. Phys. Lett. 88 (2006) 10-13, doi:http://dx.doi.org/10.1063/1.2183366.

[24] Y. Dai, G.M. Swain, M.D. Porter, J. Zak, New horizons in spectroelectrochemical measurements: optically transparent carbon electrodes, Anal. Chem. 80 (2008) 14-22, doi:http://dx.doi.org/10.1021/ac085996r.

[25] D. Neubauer, J. Scharpf, A. Pasquarelli, B. Mizaikoff, C. Kranz, Combined in situ atomic force microscopy and infrared attenuated total reflection spectroelectrochemistry, Analyst 138 (2013) 6746-6752, doi:http://dx.doi.org/ 10.1039/c3an01169k.

[26] M. Chiku, T.A. Ivandini, A. Kamiya, A. Fujishima, Y. Einaga, Direct electrochemical oxidation of proteins at conductive diamond electrodes, J. Electroanal. Chem. 612 (2008) 201-207, doi:http://dx.doi.org/10.1016/j. jelechem.2007.09.027.

[27] J. Roeser, N.F.A. Alting, H.P. Permentier, A.P. Bruins, R. Bischoff, Boron-doped diamond electrodes for the electrochemical oxidation and cleavage of peptides, Anal. Chem. 85 (2013) 6626-6632, doi:http://dx.doi.org/10.1021/ ac303795c.

[28] T.A. Ivandini, E. Saepudin, H. Wardah, N. Dewangga, Y. Einaga, Development of a biochemical oxygen demand sensor using gold-modified boron doped diamond electrodes, Anal. Chem. 84 (2012) 9825-9832, doi:http://dx.doi.org/ 10.1021/ac302090y.

[29] W.T. Wahyuni, T.A. Ivandini, E. Saepudin, Y. Einaga, Development of neuraminidase detection using gold nanoparticles boron-doped diamond electrodes, Anal. Biochem. 497 (2016) 68-75, doi:http://dx.doi.org/10.1016/j. ab.2015.12.003.

[30] T.A. Ivandini, W.P. Wicaksono, E. Saepudin, B. Rismetov, Y. Einaga, Anodic stripping voltammetry of gold nanoparticles at boron-doped diamond electrodes and its application in immunochromatographic strip tests, Talanta 134 (2015) 136-143, doi:http://dx.doi.org/10.1016/j.talanta.2014.11.010.

[31] J. Izquierdo, B. Mizaikoff, C. Kranz, Surface-enhanced infrared spectroscopy on boron doped diamond modified with gold nanoparticles for spectroelectrochemical analysis, Phys. Status Solidi 213 (2016) 2056-2062, doi:http://dx.doi.org/10.1002/pssa.201600222.

[32] R. Lu, W.-W. Li, A. Katzir, Y. Raichlin, H.-Q. Yu, B. Mizaikoff, Probing the secondary structure of bovine serum albumin during heat-induced denaturation using mid-infrared fiberoptic sensors, Analyst 140 (2015) 765770, doi:http://dx.doi.org/10.1039/c4an01495b.

[33] D.H. Tsai, M. Davila-Morris, F.W. Delrio, S. Guha, M.R. Zachariah, V.A. Hackley, Quantitative determination of competitive molecular adsorption on gold nanoparticles using attenuated total reflectance-fourier transform infrared spectroscopy, Langmuir 27 (2011) 9302-9313, doi:http://dx.doi.org/10.1021/ la2005425.

[34] C.T. Middleton, P. Marek, P. Cao, C. Chiu, S. Singh, A.M. Woys, et al., Twodimensional infrared spectroscopy reveals the complex behaviour of an amyloid fibril inhibitor, Nat. Chem. 4 (2012) 355-360, doi:http://dx.doi.org/ 10.1038/nchem.1293.
[35] M. Bhattacharya, N. Jain, S. Mukhopadhyay, Insights into the mechanism of aggregation and fibril formation from bovine serum albumin, J. Phys. Chem. B 115 (2011) 4195-4205, doi:http://dx.doi.org/10.1021/jp111528c

[36] I. De La Arada, C. Seiler, W. Mäntele, Amyloid fibril formation from human and bovine serum albumin followed by quasi-simultaneous Fourier-transform infrared (FT-IR) spectroscopy and static light scattering (SLS), Eur. Biophys. J. 41 (2012) 931-938, doi:http://dx.doi.org/10.1007/s00249-012-0845-1.

[37] B. Shivu, S. Seshadri, J. Li, K.A. Oberg, V.N. Uversky, A.L. Fink, Distinct $\beta$-sheet structure in protein aggregates determined by ATR-FTIR spectroscopy, Biochemistry 52 (2013) 5176-5183, doi:http://dx.doi.org/10.1021/bi400625v.

[38] M. Brucherseifer, C. Kranz, B. Mizaikoff, Combined in situ atomic force microscopy-infrared-attenuated total reflection spectroscopy, Anal. Chem. 79 (2007) 8803-8806, doi:http://dx.doi.org/10.1021/ac071004q.

[39] Y.F. Bai, T. Bin Xu, J.H.T. Luong, H.F. Cui, Direct electron transfer of glucose oxidase-boron doped diamond interface: a new solution for a classical problem, Anal. Chem. 86 (2014) 4910-4918, doi:http://dx.doi.org/10.1021/ ac501143e.

[40] H. Notsu, T. Fukazawa, T. Tatsuma, D.A. Tryk, A. Fujishima, Hydroxyl groups on boron-doped diamond electrodes and their modification with a silane coupling agent, Electrochem. Solid-State Lett. 4 (2001) H1-H3, doi:http://dx. doi.org/10.1149/1.1346556.

[41] H. Notsu, T. Tatsuma, A. Fujishima, Tyrosinase-modified boron-doped diamond electrodes for the determination of phenol derivatives, J. Electroanal. Chem. 523 (2002) 86-92, doi:http://dx.doi.org/10.1016/S0022-0728(02)00733-7.

[42] D. Enders, T. Nagao, A. Pucci, T. Nakayama, Reversible adsorption of $\mathrm{Au}$ nanoparticles on SiO2/Si: an in situ ATR-IR study, Surf. Sci. 600 (2006) L71L75, doi:http://dx.doi.org/10.1016/j.susc.2006.01.019.

[43] H.B. Martin, P.W. Morrison, Application of a diamond thin film as a transparent electrode for in situ infrared spectroelectrochemistry, Electrochem. SolidState Lett. 4 (2001) E17, doi:http://dx.doi.org/10.1149/1.1353162.

[44] S.E. Moulton, J.N. Barisci, A.J. McQuillan, G.G. Wallace, ATR-IR spectroscopic studies of the influence of phosphate buffer on adsorption of immunoglobulin G to TiO2, Colloids Surf. A Physicochem. Eng. Aspects 220 (2003) 159-167, doi: http://dx.doi.org/10.1016/S0927-7757(03)00078-5.

[45] M. Baia, F. Toderas, L. Baia, D. Maniu, S. Astilean, Multilayer structures of selfassembled gold nanoparticles as a unique SERS and SEIRA substrate, ChemPhysChem 10 (2009) 1106-1111, doi:http://dx.doi.org/10.1002/ cphc.200800815.

[46] B.D. Bozic, M.L.A. Ivic, N.P. Trisovic, S.D. Petrovic, Electrochemical characterization of oxaprozin on bare gold electrode and electrode modified with bovine serum albumin, Int. J. Electrochem. Sci. 7 (2012) 1160911616.

[47] D. Reinstädler, H. Fabian, J. Backmann, D. Naumann, Refolding of thermally and urea-denatured ribonuclease A monitored by time-resolved FTIR spectroscopy, Biochemistry 35 (1996) 15822-15830, doi:http://dx.doi.org/ 10.1021/bi961810j.

[48] R. Gilmanshin, S. Williams, R.H. Callender, W.H. Woodruff, R.B. Dyer, Fast events in protein folding: relaxation dynamics of secondary and tertiary structure in native apomyoglobin, Proc. Natl. Acad. Sci. U. S. A. 94 (1997) 37093713, doi:http://dx.doi.org/10.1073/pnas.94.8.3709.

Please cite this article in press as: A.I. López-Lorente, et al., Boron-doped diamond modified with gold nanoparticles for the characterization of bovine serum albumin protein, Vib. Spectrosc. (2016), http://dx.doi.org/10.1016/j.vibspec.2016.10.010 